\title{
Implementation of Sustainable Practices in Textile Processing Mills of Lahore, Pakistan
}

\author{
Sohail Ali Naqvi', Masood Arshad ${ }^{1}$, Assad Farooq ${ }^{2}$, Farah Nadeem ${ }^{1 *}$ \\ ${ }^{1}$ WWF-Pakistan, Lahore, Pakistan \\ ${ }^{2}$ University of Agriculture, Faisalabad, Pakistan
}

Received: 6 June 2018

Accepted: 18 October 2018

\begin{abstract}
This project study assesses the effectiveness of sustainable practices for minimizing water use, energy conservation and wastewater pollution reduction in 21 textile processing units of Lahore, Pakistan that volunteered and participated in the project study. Detailed assessment audits were conducted to identify the hotspot inefficient areas in terms of water, energy and wastewater. After that, the most feasible best techniques for cleaner production were deciphered through a multi-criteria decision-making process. A total of 45 techniques were listed. Each suggested option was discussed thoroughly with the management of the mills in order to determine their economic viability and techno-applicability. Business case scenarios were built with investment options and payback times for all techniques. Each mill chose the practices most suitable to them and implemented the selected best water management practices and cleaner production techniques with the help of the project team, which conducted regular audits of all mills in order to assess the implementation process and to determine improvements caused by sustainable practice. It was observed that approximately $67 \%$ of selected industries achieved a $10-30 \%$ reduction in wastewater pollution. All mills achieved a water consumption reduction ranging $1-19.5 \%$. Furthermore, $80 \%$ of industries also achieved an improvement in their energy efficiency ranging $0.2-60 \mathrm{MJ} \times 10^{6} /$ Year.
\end{abstract}

Keywords: cleaner production, best available techniques, sustainable production, textile, water management

\section{Introduction}

Industrial activities contribute massively to water pollution. Keeping in view the rate of industrialization and economic growth, it is expected that the global water demand would increase to as much as 1500 billion $\mathrm{m}^{3}$ by the year 2030 [1]. Globally, water sustainability and

*e-mail: fanadeem@wwf.org.pk pollution prevention is recognized as a significant issue that needs immediate attention [2]. Textile industries are highly water intensive and also produce considerable wastes and effluents [3]. The repeated rinsing process for removing unfixed dyes results in huge amounts of water consumption [4] and simultaneously augments wastewater generation [5]. Therefore, reduction in volume of water consumed is a major concern for textile industries [6].

Over the last two decades, multiple methods of sustainable production have been developed [7]. 
Cleaner production methods are aimed at preventing huge volumes of resource consumption and also target reduction of pollution generation [8]. This is achieved through identification of processes during production that can be tailored to become more resource efficient [9]. Furthermore, when industries adopt cleaner production technologies, they tend to reduce their production costs, meet the environmental policies and regulations of their country and also improve their competitiveness in the market [10].

Integrated pollution prevention and control (IPPC) was the primary European framework with directives for environmental performance monitoring in industries. It includes the use of best available techniques (BAT) present in BAT reference documents called BREFs. These are usually used as a reference when choosing best practices for water management in textile industries. Countries outside the European Union such as Turkey also follow these BREFs to promote sustainable water use in their industries [11].

In 2013, Ibanez-Fores et al. [12] suggested a method for recognizing sustainable and most relevant BATs for industrial units. This method revolved around the life cycle assessment (LCA) approach in order to select the most suitable BAT options for pollution control and water conservation. The method was illustrated by implementation on a ceramic tile-making unit.

However, in 2015, Ozturk et al. [13] worked specifically on the textile industry and recommended that control methods within the plant of textile industries can be useful in decreasing water and energy consumption. Their methodology included a comprehensive plant survey to identify recoverable streams and the evaluation of unnecessary water usage in a textile mill. Moreover, the wastewater generation was estimated and its characterization was also conducted. Their study demonstrated that implementing BATs could result in enhancing the water efficiency of the mill.

\section{Textile Industry in Pakistan}

The textile sector is the largest industry of Pakistan in terms of labor force employment, exports and production. Globally, Pakistan is ranked No. 12 among textile product exporters. It contributes $8.5 \%$ to Pakistan's GDP and $52 \%$ in exports. Conspicuous textile products in Pakistan include fabrics made out of cotton, knitwear (hosiery), cotton yarn, bed wares, readymade garments, towels, synthetic textiles and unprocessed cotton [14]. As far as water consumption is concerned, large industries are more water efficient as their investment size is high compared to small and medium enterprises. Additionally, medium industry manufactures high-quality products with conventional machinery. The efficiency of the processes is thus compromised and resource management is not at its optimum. On the contrary, small industries are involved in small-scale specific productions and are less of a burden on natural resources.

\section{Water and Chemical Consumption in the Textile Industry}

In a textile mill, wet processes like dyeing and washing require high inputs of water. The ranges of water consumption on average are between 3 to $932 \mathrm{~L} / \mathrm{Kg}[15,16]$. Furthermore, high chemical consumption is characteristic of textile processes [17]. In Pakistan, according to the cleaner production institute, Pakistan (CPI), in the textile processing sector, an industry with water consumption of $75 \mathrm{~L} / \mathrm{Kg}$ of product or less is considered water efficient. Those ranging between $76-200 \mathrm{~L} / \mathrm{Kg}$ are moderately efficient and those with water consumption of greater than $200 \mathrm{~L} / \mathrm{Kg}$ of product are water inefficient. CPI also assesses that about 53\% industries range between moderately water efficient and inefficient. In terms of pollution load, the textile BREF document of IPPC specifies that COD levels of textile effluents range between 13 and $390 \mathrm{~g} \mathrm{COD} / \mathrm{Kg}$ product [18]. Additionally, textile wastewater is difficult to treat and identifying the correct approach of cleaner production may be challenging [19]. However, there have been successful studies that claim that COD loads of textile wastewater may be decreased by $25-50 \%$ through implementation of proper cleaner production methods $[20,21]$. The multi-criteria decision-making method is usually a useful method in determining eco-friendly options for sustainable production [22].

In Pakistan, environmental regulations are not the key drivers of cleaner production initiatives. Pressure from international businesses that are customers of Pakistani textile industries is the main reason for industries to invest in cleaner production options. Furthermore, long-term cost reductions are also a motivating factor in this regard [23]. Considering these factors, a project was conducted to evaluate and assess the implementation of various BATs to reduce wastewater generation and improve water and energy conservation.

The main objectives of this research project were to help and guide textile industries towards cleaner and sustainable water management practices. The study targeted 21 industries that extended their cooperation and support for the initiative. Their willingness to tread the path of sustainability was the primary success of the study, which aimed to reduce water consumption and pollution load in the participant industries depending on the extent of changes made in their processes. BATs applied for water management in the project were called as best water management practices (BWMPs). 


\section{Methodology}

The study was carried out in three phases (Fig. 1). In the first stage, the selected industries were surveyed for on-site investigations. An in depth audit was conducted of all processes occurring in the textile industry in order to identify inefficient areas where best practices for water management, energy conservation and wastewater pollution reduction could be suggested and implemented. The audits were conducted under the UNEP framework for environmental audit methodology. Data was collected for water consumed during the production processes and COD levels in wastewater.

The second phase of the research and implementation project involved determining BATs/BWMP options on the basis of the IPPC and recommendations by the project team. Multi-dimensional analysis tools aided in the selection of relevant BATs/BWMPs [24]. The recommendations were given and follow-up surveys were conducted to see the implementation of BATs/ BWMPs. Furthermore, calculations were made for water efficiency status and wastewater pollution load status for all 21 industries included in the study.

In the third phase, water management, energy conservation and pollution problems were listed, and their potential BATs/BWMPs solutions identified and delineated along with the investments required for implementation and their payback times. The BATs/BWMPs were divided into three business case categories based on business priority: i) Frequently implemented with very high payback periods ii) Important with moderate to high payback periods and iii) Absolute, i.e., comprising a full menu of BATs/ BWMPs mentioned in the above two categories. The first set of options were those that were not too

\begin{tabular}{|l|}
\hline Phase1: On-site Survey \\
- Detailed on -site audit of all processes \\
- Data collection on water consumption during the production \\
processes and COD levels of wastewater \\
- Identification of inefficient areas
\end{tabular}

\begin{tabular}{l} 
Phase 2: Assessment \\
\begin{tabular}{l} 
- Calculations done for water efficiency status and wastewater \\
pollution load status for all 21 industries. \\
- Determination of BAT/BWMP options on the basis of IPCC \\
and recommendations of CPI. \\
\hline Phase 3: Feasibiity Study \\
- The Best Available techniques were divided into three \\
Business Case categories based on business priority \\
- Determinaton of Investments and payback times \\
- Discussion will industry management for feasibility \\
analaysis and implementation plan
\end{tabular} \\
\hline
\end{tabular}

Fig. 1. Framework for the methodology used in the study. hard to implement; were low-cost and the payback time was less. Examples of such techniques include reusing cooling water and the $\mathrm{RO}$ rejected water. The second scenario included options that were important for achieving environmental sustainability but they were high-cost techniques and their payback times also ranged between one to three years. The third business scenario included implementation of all BATs/BWMPs. The 21 industries included in the study were presented with all three scenarios.

The solutions were proposed to the technical management of the industries, and financial feasibility and technical viability were discussed. The industries were mobilized to implement absolute or any set of options as per their requirements and priorities. Once the above-mentioned process was complete and the industries had implemented the recommended BATs/BWMPs according to their feasibility, the impacts of the implementation of BATs/BWMPs were calculated after detailed surveys and collection of data from the industries. The parameters included in the study of impacts were percentage reduction in water consumption, chemical recovery (Kg/Year) and annual saving in millions (Pakistani Rupees/PKR).

\section{Results and Discussion}

The specific water consumption, wastewater production and COD levels in wastewater for all 21 industries are presented in Table 1.

The results highlighted that only 2 out of the 21 industries were water efficient, 13 were moderately water efficient and 6 were inefficient as per the Cleaner Production Institute standard of water consumption of $75 \mathrm{~L} / \mathrm{Kg}$ of product considered as water efficient. As far as the COD levels are concerned, all textile mills had high levels of COD in the wastewater produced per day. In order to establish environmental sustainability, BAT/BWMP options were considered to increase water and energy efficiency of the mills as well as to reduce water pollution loads.

\section{BATs/BWMPs}

A detailed survey of the industries was conducted to identify areas where best practices could be applied to initiate sustainable production in the mills. In 2013, Greer et al. [25] suggested that it can be deciphered from the literature that by implementing such practices, water use may be reduced by $1-6 \%$ and energy by $0.3-10 \%$. The identified BATs/BWMPs for water conservation, energy conservation and wastewater pollution reduction are as follows:

\section{Practices to Reduce Water Consumption}

1. Maintaining pipes and improving their quality and condition to control any leaking. 
Table 1. Water consumption, wastewater production and COD levels in wastewater,

\begin{tabular}{|c|c|c|c|c|}
\hline $\begin{array}{c}\text { Industry } \\
\text { No. }\end{array}$ & $\begin{array}{c}\text { Production } \\
(\mathrm{kg} / \mathrm{d})\end{array}$ & $\begin{array}{c}\text { Water } \\
\text { Consumption } \\
(\text { (Liter/Kg } \\
\text { of Product) }\end{array}$ & $\begin{array}{c}\text { Wastewater } \\
\text { Production } \\
\text { (Liter/Kg } \\
\text { of Product) }\end{array}$ & $\begin{array}{c}\text { COD } \\
\text { (Kg/day) }\end{array}$ \\
\hline 1 & 31,487 & 131 & 118 & 3610 \\
\hline 2 & 26,522 & 130 & 117 & 2555 \\
\hline 3 & 13,759 & 215 & 177 & 2077 \\
\hline 4 & 38,427 & 74 & 61 & 1304 \\
\hline 5 & 25,465 & 97 & 82 & 2419 \\
\hline 6 & 22,743 & 98 & 81 & 4188 \\
\hline 7 & 8,617 & 313 & 257 & 2174 \\
\hline 8 & 4,267 & 157 & 135 & 1115 \\
\hline 9 & 42,990 & 94 & 71 & 2419 \\
\hline 10 & 26,676 & 142 & 121 & 3374 \\
\hline 11 & 32,016 & 80 & 67 & 4689 \\
\hline 12 & 16,093 & 88 & 71 & 3230 \\
\hline 13 & 32,864 & 103 & 81 & 2142 \\
\hline 14 & 25,465 & 231 & 199 & 9706 \\
\hline 15 & 54,900 & 66 & 60 & 5214 \\
\hline 16 & 26,475 & 82 & 69 & 2358 \\
\hline 17 & 4,320 & 177 & 161 & 201 \\
\hline 18 & 8,890 & 427 & 337 & 770 \\
\hline 19 & 15,240 & 350 & 318 & 12683 \\
\hline 20 & 53,000 & 132 & 91 & 8635 \\
\hline 21 & 5,334 & 372 & 326 & 776 \\
\hline
\end{tabular}

2. Reusing the cooling water from processes such as singeing, therm oil heaters, cooling drums, compressors, caustic recovery plants, chillers, etc.

3. Reusing the RO rejected water for spraying at boiler wet scrubber/cyclones or processes that do not require high quality of water.

4. Reducing the diameter of the pipes to decrease water use.

5. Using water showering technique in rope and jigger machines for washing of fabric.

6. Using wastewater at boiler wet scrubbers instead of freshwater and wastewater mechanical screens can also be washed with the same.

7. Controlling of washing points to avoid any wastage of water.

8. Cleaning of printing machine screens by water hoses with nozzles.

9. Installing trigger nozzles to improve water efficiency.

10. Reusing the water used for process washing for washing in other processes.
11. Collecting and reusing blanket washing water. The Synchronization of blanket washing water with the movement of printing machine can help avoid water wastage during machine shut off.

12. Installing automatic level control switches at water storage tanks.

13. Installing water flow meters.

14. Collecting and reusing the soaper.

15. Using wastewater for washing pigment drums as well as cleaning color kitchen floors.

16. Cleaning wet floors contaminated with chemicals through dry cleaning methods.

17. Creating awareness and sensitizing workers about the importance of water conservation, energy efficiency and pollution reduction.

18. The machines should have automatic shut-off valves.

19. Washing printing machine screens by a washing machine installed for the purpose.

20. Disposing the boiler ash in dry state.

\section{Practices for Energy Conservation}

1. Changing the already existing machines to countercurrent mode in order to improve energy and water efficiency.

2. Installing temperature and pressure gauges at process vessels

3. Monitoring the performance of motors to improve efficiency.

4. Using copper wires for rewinding motors as they are more energy efficient.

5. Noting the number of times a motor has been rewound in record so that the process should not be repeated more than three to four times.

6. Reusing the steam condensate as boiler feed water.

7. Monitoring the TDS levels in the boiler water and boiler blow down be conducted.

8. Installing temperature controllers and steam flow meters.

9. Installing energy-efficient motors.

10. Installing energy-efficient water turbines.

11. Placing a steam and condensate recovery system.

12. Placing heat exchangers in hot wastewater streams.

13. Preheating process streams with flue gases of generators/oil heater exhaust to conserve energy.

14. Using motors with inverters.

\section{Practices to Reduce Wastewater Pollution}

1. Reusing process washes that have a low chemical content can be used to make chemical solutions.

2. Reusing the residual printing paste for the same process or disposed of in dry state.

3. Monitoring and optimizing the amount of chemicals consumed.

4. Reducing the amount of bleach used for fabrics dyed black or very dark.

5. Collecting leaks and spills in catch pans. 
Table 2. Business Case Scenario-01: Frequently implemented with very high payback periods.

\begin{tabular}{|c|c|c|c|}
\hline \multirow[b]{2}{*}{ Business Priority-01 Solution Options } & \multicolumn{3}{|c|}{ Financial Overview } \\
\hline & $\begin{array}{l}\text { Investment } \\
\text { PKR } 000\end{array}$ & $\begin{array}{l}\text { Saving } \\
\text { PKR } 000\end{array}$ & $\begin{array}{c}\text { Simple } \\
\text { Payback } \\
\text { (Months) }\end{array}$ \\
\hline \multicolumn{4}{|l|}{ Water Management } \\
\hline Leakage control, maintenance of pipelines, piping improvement & $10-100$ & $20-200$ & 6 \\
\hline $\begin{array}{l}\text { Collection and reuse of cooling water from singeing, compressors, therm oil heaters, } \\
\text { chillers, cooling drums, caustic recovery plant etc in the process }\end{array}$ & $15-100$ & $30-200$ & 6 \\
\hline $\begin{array}{l}\text { Reuse of RO rejected water/softener regeneration water for showering at boiler wet } \\
\text { scrubber/cyclones or in the process where high quality water is not required }\end{array}$ & $30-60$ & $60-120$ & 6 \\
\hline Use of reduced sized diameter pipes for water use & $20-100$ & $30-150$ & 8 \\
\hline $\begin{array}{l}\text { Implementing water showering at fabric in rope and jigger machines for effective washing } \\
\text { with optimum water consumption }\end{array}$ & $5-50$ & $6-60$ & 10 \\
\hline $\begin{array}{l}\text { Use of wastewater instead of fresh water at boiler wet scrubber and for cleaning } \\
\text { of wastewater mechanical screens }\end{array}$ & $25-100$ & $30-120$ & 10 \\
\hline Control of floor and other washing points & $10-50$ & $12-60$ & 10 \\
\hline Use of nozzles at water hoses to clean printing machine screens & $10-15$ & $15-25$ & 8 \\
\hline Installation of water trigger nozzles at water hoses & $10-15$ & $15-25$ & 8 \\
\hline Reuse of process washes of one process as washing water for other processes & $20-100$ & $25-125$ & 10 \\
\hline $\begin{array}{l}\text { Collection and reuse of blanket washing water, Synchronize blanket washing with printing } \\
\text { machine movement to avoid water wastage during machine shut off machine }\end{array}$ & $15-50$ & $25-85$ & 7 \\
\hline Installation of automatic level control switches at water storage tanks & $10-50$ & $11-55$ & 11 \\
\hline Installation of water flow meters & $10-200$ & $11-220$ & 11 \\
\hline $\begin{array}{c}\text { Collection and reuse of soaper wastewater for washing pigment drums and color kitchen } \\
\text { floor cleaning }\end{array}$ & $50-100$ & $60-120$ & 10 \\
\hline Use of dry cleaning methods to clean the wet floor contaminated with chemicals & $5-10$ & $6-11$ & 11 \\
\hline \multicolumn{4}{|l|}{ Energy Conservation } \\
\hline Change existing machines to countercurrent mode to reduce energy and water consumption & $10-75$ & $12-90$ & 10 \\
\hline Installation of temperature and pressure gauges at process vessels & $5-50$ & $6-60$ & 10 \\
\hline $\begin{array}{c}\text { Monitoring and evaluation of motors performance and improve system accordingly (loading } \\
\text { adjustment, replacing over/under sized motors) }\end{array}$ & $50-300$ & $75-450$ & 8 \\
\hline Use of high quality copper wires for rewinding of motors & $50-200$ & $55-220$ & 11 \\
\hline Keep record of motors rewinding and replace motors after three to four times of rewinding & $100-200$ & $120-240$ & 10 \\
\hline Collection and reuse of steam condensate as boiler feed water & $100-150$ & $625-1200$ & 2 \\
\hline Conduct boiler blow down after measuring TDS levels in the boiler water & $10-20$ & $30-60$ & 4 \\
\hline \multicolumn{4}{|l|}{ Wastewater Pollution Reduction } \\
\hline Reuse of process washes containing low content of chemicals for making chemical solutions & $100-250$ & $245-610$ & 5 \\
\hline $\begin{array}{l}\text { Collection of residual printing paste from pigment drums and pumps to use in the process } \\
\text { again or disposing it off in dry state }\end{array}$ & $25-50$ & $35-65$ & 9 \\
\hline $\begin{array}{l}\text { Monitoring chemical consumption at process recipes (use of calibrated beakers for chemical } \\
\text { dosing) }\end{array}$ & $5-10$ & $10-20$ & 6 \\
\hline Apply less extensive bleaching for those fabrics which undergo black or dark shaded dyeing & - & $50-120$ & - \\
\hline Chemical storage with catch pans underneath chemical containers to collect leaks and spills & $50-200$ & $55-220$ & 11 \\
\hline $\begin{array}{l}\text { Collect and dispose solid waste at appropriate dumping site instead of throwing } \\
\text { into wastewater drains }\end{array}$ & $10-50$ & - & - \\
\hline Total & $760-2,655$ & $1,674-4,931$ & $\begin{array}{c}5-6 \\
\text { (Average) }\end{array}$ \\
\hline
\end{tabular}


Table 3. Business Case Scenario-02: Important with moderate to high payback periods.

\begin{tabular}{|c|c|c|c|}
\hline \multirow[b]{2}{*}{ Solution Options } & \multicolumn{3}{|c|}{ Financial Overview } \\
\hline & $\begin{array}{l}\text { Investment } \\
\text { PKR } 000\end{array}$ & $\begin{array}{c}\text { Saving } \\
\text { PKR } 000\end{array}$ & $\begin{array}{c}\text { Simple } \\
\text { Payback } \\
\text { (Months) }\end{array}$ \\
\hline \multicolumn{4}{|l|}{ Water Management } \\
\hline $\begin{array}{c}\text { Conduct training of workers and managers on water conservation, energy ef- } \\
\text { ficiency and pollution reduction aspects }\end{array}$ & $200-300$ & - & - \\
\hline Installation of automatic water shut off valves at machines & $500-1,000$ & $165-330$ & 36 \\
\hline Installation of washing machine for printing machine screens & $60-70$ & $30-35$ & 24 \\
\hline Disposal of boiler ash in dry state instead of washing it in the drain with water & $300-3,000$ & $100-1,000$ & 36 \\
\hline \multicolumn{4}{|l|}{ Energy Conservation } \\
\hline Installation of temperature controllers, steam flow meters etc & $400-600$ & $265-400$ & 18 \\
\hline Installation of energy efficient motors & $1,000-2,000$ & $925-1,850$ & 13 \\
\hline Installation of efficient water turbines & $200-300$ & $160-240$ & 15 \\
\hline Installation of efficient steam and condensate recovery system & $1,000-3,000$ & $800-2,400$ & 15 \\
\hline Installation of heat exchangers at hot wastewater streams & $500-750$ & $500-750$ & 12 \\
\hline Preheating of process streams with flue gases of generators/oil heater exhaust & $1,000-2,000$ & $1,000-2,000$ & 12 \\
\hline Inverters on motors & $200-400$ & $200-400$ & 12 \\
\hline \multicolumn{4}{|l|}{ Wastewater Pollution Reduction } \\
\hline Installation of caustic recovery plant & $3,000-4,000$ & $3,000-4,000$ & 12 \\
\hline Use of treated water with $\mathrm{RO} /$ softener & $1,000-2,000$ & $500-1,000$ & 24 \\
\hline Automatic chemical dispensing system & $2,000-3,000$ & $650-1,000$ & 36 \\
\hline Establishing laboratory for chemicals purity monitoring & $500-1,000$ & $160-350$ & 36 \\
\hline Disposal of boiler ash in dry state instead of washing with water in the drain & - & - & - \\
\hline Total & $11,860-23,420$ & $8,455-15,755$ & $\begin{array}{c}17-18 \\
\text { (Average) }\end{array}$ \\
\hline
\end{tabular}

6. Solid waste should not be thrown in wastewater drains.

7. Installing caustic recovery plant.

8. Using treated water with $\mathrm{RO} /$ softener.

9. Using an automatic chemical dispensing system.

10. Establishing a laboratory for chemical purity monitoring.

11. Disposing of boiler ash in a dry state rather than through washing.

All solution options were divided into the business case scenarios described in the methodology section along with their financial overview. Table 2 shows all the BATs/BWMPs delineated into Business Case Scenario 1 along with the investment required, savings expected and the payback period in months. Table 3 shows all options suitable for Business Case Scenario 2. The textile processing sector first priority set of BATs/BWMPs implementation had a very clear business case. The investment amount was in the range of PKR 0.8-2.6 million, depending upon the size of the industry, pays back in less than a year with annual benefits of PKR 1.7-4.9 million, in terms of water conservation (5-30\%), chemical savings, energy efficiency (5-10\%) and pollution reduction (10-30\%). The textile processing sector's second priority set of BATs/BWMPs implementation also had a very clear business case. The investment amount was in the range of PKR 11.8-23.4 million, depending upon the size of the industry, which pays back in less than two years with annual benefits of PKR 8.5-15.8 million in terms of water conservation (5-30\%), chemical savings, energy efficiency $(5-10 \%)$ and pollution reduction (10-30\%). The textile processing sector absolute set of BATs/ BWMPs, which included a full implementation of all two above-mentioned scenarios, included an investment amount in the range of PKR 12.6-26.1 million, depending upon the size of the industry, paid back in less than one and half years with annual benefits of PKR 10.1-20.7 million, in terms of water conservation (5-30\%), chemical savings, energy efficiency (5-10\%) and pollution reduction (10-30\%). 
Table 4. Impacts of BATs/BWMPs implemented in 21 textile industries in Lahore, Pakistan.

\begin{tabular}{|c|c|c|c|c|c|c|c|c|}
\hline \multirow[b]{2}{*}{$\begin{array}{l}\text { Industry } \\
\text { No. }\end{array}$} & \multirow[b]{2}{*}{$\begin{array}{l}\text { Investment } \\
\text { (Million } \\
\text { PKR) }\end{array}$} & \multicolumn{6}{|c|}{ Impacts of BATs/BWMPs } & \multirow[b]{2}{*}{$\begin{array}{l}\text { Payback } \\
\text { Time } \\
\text { (Months) }\end{array}$} \\
\hline & & $\begin{array}{c}\text { Water } \\
\text { Reduction } \\
\left(\mathrm{m}^{3} / \text { Year }\right)\end{array}$ & $\begin{array}{l}\% \text { Water } \\
\text { Use } \\
\text { Reduction }\end{array}$ & $\begin{array}{c}\text { Energy } \\
\text { Reduction } \\
\text { (MJ x 106/Year) }\end{array}$ & $\begin{array}{l}\text { Chemical } \\
\text { Recovery } \\
\text { (Kg/Year) }\end{array}$ & $\begin{array}{l}\text { Pollution } \\
\text { Reduction } \\
(10-30 \%)\end{array}$ & $\begin{array}{l}\text { Annual saving } \\
\text { (Million PKR) }\end{array}$ & \\
\hline 1 & 2.567 & 89,320 & 7.5 & 2.0 & 15,950 & Yes & 7.99 & 3.6 \\
\hline 2 & 0.953 & 211,617 & 19.5 & 2.0 & - & Yes & 2.64 & 4.3 \\
\hline 3 & 0.027 & 19,600 & 4 & 1.3 & - & $<10$ & 1.00 & 0.4 \\
\hline 4 & 0.666 & 16,275 & 14 & 0.3 & - & $<10$ & 0.29 & 27.6 \\
\hline 5 & 0.083 & 112,200 & 15 & 34.0 & - & $<10$ & 0.89 & 1.0 \\
\hline 6 & 3.985 & 67,200 & 7 & 5.0 & 181,632 & Yes & 16.76 & 2.8 \\
\hline 7 & 3.290 & 56,100 & 11 & 6.2 & 204,000 & Yes & 19.00 & 2.0 \\
\hline 8 & 3.530 & 31,250 & 5 & 3.0 & 175,000 & Yes & 14.54 & 2.8 \\
\hline 9 & 1.115 & 29,000 & 14 & 3.5 & 15,000 & Yes & 3.06 & 4.0 \\
\hline 10 & 3.515 & 11,600 & 1 & - & 164,604 & Yes & 11.56 & 3.6 \\
\hline 11 & 5.810 & 61,750 & 5 & 23.9 & 245,960 & Yes & 34.55 & 2.0 \\
\hline 12 & 0.235 & 119,750 & 13 & 60.0 & - & $<10$ & 6.27 & 0.5 \\
\hline 13 & 3.525 & 93,960 & 10 & 1.4 & 279,648 & Yes & 21.32 & 2.0 \\
\hline 14 & 0.130 & 85,150 & 4.5 & 0.92 & 204,750 & Yes & 15.17 & 1.0 \\
\hline 15 & 0.135 & 55,825 & 9 & 0.2 & 94,050 & Yes & 3.55 & 0.5 \\
\hline 16 & 3.580 & 63,000 & 5 & 2.8 & 191,565 & Yes & 15.58 & 2.7 \\
\hline 17 & 28.975 & 330,000 & 17 & 17 & - & Yes & 13.55 & 25.5 \\
\hline 18 & 2.125 & 7,500 & 1 & 0.24 & - & Yes & 0.19 & 131.4 \\
\hline 19 & 0.051 & 31,938 & 3 & - & - & $<10$ & 0159 & 3.8 \\
\hline 20 & 1.710 & 79,205 & 3 & - & - & $<10$ & 2.22 & 9.2 \\
\hline 21 & 0.375 & 69,351 & 31 & - & - & $<10$ & 0.34 & 12.9 \\
\hline
\end{tabular}

\section{Level of Success Achieved}

Table 4 presents the impacts of implementation of BATs/BWMPs in 21 textile industries of Lahore, Pakistan. It can be observed that approximately $67 \%$ of industries achieved a $10-30 \%$ reduction in wastewater pollution. All mills achieved a water consumption reduction ranging between 1-19.5\%. Furthermore, 17 industries also achieved a certain level of improvement in their energy efficiency. These achievements are attributed to the detailed audits of the industries, identification of inefficient areas in terms of water consumption, energy consumption and wastewater pollution and implementation of BATs/ BWMPs to improve the efficiency of the processes so that the industries may contribute to environmental sustainability.

\section{Conclusions}

This study involved the implementation and assessment of the most relevant and sustainable BATs/BWMPs for reducing water consumption, conserving energy and wastewater pollution reduction in 21 textile processing mills of Lahore, Pakistan. The primary audits indicated that only 2 out of the 21 industries were water efficient, 13 were moderately water efficient, and 6 were inefficient as per the Cleaner Production Institute standard of water consumption of $75 \mathrm{~L} / \mathrm{Kg}$ of product considered as water efficient. As far as the COD levels are concerned, all textile mills had high levels of COD in the wastewater produced per day. In order to establish environmental sustainability, BAT/BWMP options were considered to increase water and energy efficiency of the mills as well as to reduce water pollution loads. Business cases were 
calculated and presented to industry management and the economic feasibility and techno-applicability of the options was considered. Post implementation audits were conducted in order to deduce the improvements in water and energy efficiency of the mills as well as reduce wastewater pollution. Approximately $67 \%$ of industries achieved a $10-30 \%$ reduction in wastewater pollution. All textile mills achieved a water consumption reduction ranging between $1-19.5 \%$. Moreover, 17 mills also improved their energy efficiency by $0.2-60 \mathrm{MJ} \times 10^{6} /$ Year.

\section{Acknowledgements}

This project study was funded by the European Union under its SWITCH-Asia programme and was executed by the consortium of three organizations, i.e., WWF-Pakistan, WWF-UK and Cleaner Production Institute, Pakistan (CPI). The cooperation of the textile mills management is also appreciated by the authors. The Lahore Chamber of Commerce and Industry (LCCI) and the Punjab Small Industries Corporation (PSIC) were associates of the project.

The publication of this project study was supported by the project "International Labor and Environmental Standards (ILES) Application in Pakistan's SMEs," which is also funded by the European Union. The research findings, recommendations and conclusions drawn from this publication are also a part of ILES project activities and are being implemented in the textile sector in Pakistan. This publication has been produced with the assistance of the European Union. The contents of this publication are the sole responsibility of the authors and can in no way be taken to reflect the views of WWF-Pakistan or the European Union.

\section{Conflict of Interest}

The authors declare no conflict of interest.

\section{References}

1. VAJNHANDL S., VALH J.V. The status of water reuse in European textile sector. J. Environ. Manag, 141, 29, 2014.

2. MUGHEES W., AL-AHMAD M. Application of water pinch technology in minimization of water consumption at a refinery. Comput. Chem. Eng, 73, 34, 2015.

3. PARISI M.L., FATARELLA E., SPINELLI D., POGNI R., BASOSI R. Environmental impact assessment of an ecoefficient production for coloured textiles. J. Clean. Prod, 108, 514, 2015.

4. XU C.K., CHENG H., LIAO Z.J. Towards Sustainable Growth in the Textile Industry: A Case Study of Environmental Policy in China. Pol. J. Environ. Stud. 27 (5), 2325, 2018

5. KOCABAS A.M. Improvements in Energy and Water Consumption Performances of a Textile Mill after BAT
Applications (M.Sc. thesis). METU Environmental Engineering Dept., Ankara, 2008.

6. OZTURK E., KOSEOGLU H., KARABOYACI M., YIGIT N.O., YETIS U., KITIS M. Minimization of water and chemical use in a cotton/polyester fabric dyeing textile mill. J. Clean. Prod, 130, 92, 2016.

7. BEVILACQUA M., CIARAPICA E., MAZZUTO G., PACIAROTTI C. Environmental analysis of a cotton yarn supply chain. J. Clean. Prod, 82, 154, 2014.

8. ALKAYA E., DEMIRER G.N. Sustainable textile production: A case study from a woven fabric manufacturing mill in Turkey. J. Clean. Prod, 65, 595, 2014.

9. GAVRILESCU M. Proactive environmental strategies though cleaner production., International Conference on Environmental Science and Technology; Rhodes Island, Greece, 2005.

10. United Nations Environment Programme (UNEP). Green Economy and Trade,United Nations Environment Programme Trends, Challenges and Opportunities, 2013.

11. YUKSELER H., UZAL V., SAHINKAYA E., KITIS M., DILEK FB., YETIS U. Analysis of the best available techniques for wastewaters from a denim manufacturing textile mill. J. Environ. Manag, 203, 1118, 2017.

12. IBANEZ-FORES V., BOVEA M.D., AZAPAGIC A. Assessing the sustainability of Best Available Techniques (BAT): methodology and application in the ceramic tiles industry. J. Clean. Prod, 51, 162, 2013.

13. OZTURK E., YETIS U., DILEK F.B., DEMIRER G.N. A chemical substitution study for a wet processing textile mill in Turkey. J. Clean. Prod, 17, 239, 2009.

14. All Pakistan Textile Mills Association (APTMA) (Various Issues) Annual Report, 2014.

15. BRIK M., SCHOEBERL P., CHAMAM B., BRAUN R., FUCHS W. Advanced treatment of textile wastewater towards reuse using a membrane bioreactor. Process Biochem, 41, 1751, 2006.

16. COUTO C.F, MARQUES L.S, BALMANT J., DE OLIVEIRA MAIA A.P, MORAVIA W.G., SANTOS AMARAL M.C. Hybrid MF and membrane bioreactor process applied towards water and indigo reuse from denim textile wastewater. Environ Technol, 39 (6), 725, 2018.

17. OZTURK E., KARABOYACI M., YETIS U., YIGIT N.O., KITIS,M. Evaluation of integrated pollution prevention control in a textile fiber production and dyeing mill. J. Clean. Prod, 88, 116, 2015.

18. European Commission (EC). Integrated Pollution Prevention and Control (IPPC) Reference Document on Best Available Techniques for the Textile Industry (BREF). EC IPPC Bureau, Seville, 2003.

19. ALMA, T.C., DIMAS G., AHMED B., KAMEL G., LEILA C.G., RAÚL M. Assessing textile wastewater treatment in an anoxic-aerobic photobioreactor and the potential of the treated water for irrigation. Algal Res, 29, 170, 2018.

20. Danish Environmental Protection Agency (DEPA). Danish Experience Best Available Techniques-BAT in the Clothing and Textile Industry. DEPA, Copenhagen. Working Report, 2003.

21. Lebanese Cleaner Production Center (LCPC). Cleaner Production Guide for Textile Industries. Lebanese Cleaner Production Center, Beirut, Lebanon, 2010.

22. STELLA S., DAYTON M., CAMERON P., SARA P., ABDUL-SALAM J. Multi-criteria decision analysis 
framework for sustainable manufacturing in automotive industry. J. Clean. Prod, 187, 257, 2018.

23. ORTOLANO L., SANCHEZ-TRIANA E., AFZAL J., LAIQ ALI C., REBELLON S.A. Cleaner production in Pakistan's leather and textile sectors. J. Clean. Prod, 68, 121, 2014.
24. CIKANKOWITZ A., LAFOREST V. Using BAT performance as an evaluation method of techniques. J. Clean. Prod, 42, 141, 2013.

25. GREER L., KEANE S., LIN C., MEINERT J. Natural Resources Defense Council, Clean by Design, July, USA, 2013. 